\title{
Investigating the role of IT and organizational culture in adoption of organizational strategy
}

\author{
Mohammad Reza Shojaee, Fatemeh Abbasi Fashami* and Zohre Esmaili
}

Department of Management and Accounting, Ershad-Damavand Higher Education Institute, Damavand, Iran

\begin{tabular}{|c|c|}
\hline CHRON I C LE & A B S T R A C T \\
\hline $\begin{array}{l}\text { Article history: } \\
\text { Received January } 24,2014 \\
\text { Accepted } 20 \text { June } 2014 \\
\text { Available online } \\
\text { June } 252014 \\
\text { Keywords: } \\
\text { Information Technology } \\
\text { Organizational culture } \\
\text { Organizational strategy }\end{array}$ & $\begin{array}{l}\text { This study tries to examine the roles of information technology (IT) and organizational culture } \\
\text { in selecting an organization's strategy using statistical methods. It is an applied and descriptive- } \\
\text { perceptual approach. The study chooses a sample of } 171 \text { employees of Grand Tehran } \\
\text { Municipality to examine different hypotheses of the survey. Using Pearson correlation test as } \\
\text { well as regression analysis, the study concludes that there were some meaningful relationships } \\
\text { between IT and selection of an organizational strategy and organizational culture, choice and } \\
\text { significance of such strategy. Moreover, the study detected that IT and organizational culture } \\
\text { could positively and considerably influence on such a strategy. }\end{array}$ \\
\hline
\end{tabular}

(C) 2014 Growing Science Ltd. All rights reserved.

\section{Introduction}

During the past few years, there has been tremendous effort on investigating the effects of various factors for development of a good organizational strategy (Peppard et al., 2014; Shih et al., 2014). Hyvönen (2007) studied the relationships between organizational performance and customer-focused strategies, performance measures as well as information technology (IT). They reported that when a firm would not follow a customer-focused strategy, contemporary management accounting systems in combination with advanced IT was associated with high customer performance. Their results also confirmed that contemporary performance measures would not contribute on firms with a highly customer-focused strategy to achieve high customer performance. The results also indicated that a fit between the customer-focused strategy and financial performance measures could improve customer performance. Yu et al. (2013) investigated the effects of strategies, technologies, and organizational learning on development of organizational innovativeness in emerging economies. Henfridsson and Lind (2014) studied the effects of information systems strategizing, organizational sub-communities, and the emergence of a sustainability strategy.

*Corresponding author.

E-mail addresses: fereshte.abasi2003@yahoo.com (F. Abbasi Fashami) 


\subsection{Hypotheses}

Considering the research literature and review of related sources, the following hypotheses are investigated,

1. There is a meaningful relationship between IT and adoption and importance of strategy of organization.

2. There is a meaningful relationship between an organizational culture and significance of its strategy.

3. IT and organizational culture effect on adoption and importance of strategy of organization.

\subsection{Research Method}

As mentioned before, the objective of this study is to provide an applied and descriptive-perceptual approach. The authors try to examine the role of IT and organizational culture in selecting strategy of organization. In this study, we used a library method (books, articles, and computer texts) to know the relevant literature and variables of research. On the other hand, we did a field study by distributing a questionnaire among the employees of the Grand Tehran Municipality, and the study period was month of March 2014. The sample size is calculated as follows,

$$
N=Z_{\alpha / 2}^{2} \frac{p \times q}{e^{2}},
$$

where $N$ is the sample size, $p=1-q$ represents the probability, $z_{\alpha / 2}$ is CDF of normal distribution and finally $\varepsilon$ is the error term. For our study we assume $p=0.5, z_{\alpha / 2}=1.96$ and $e=0.05$, the number of sample size is calculated as $N=171$. In order to improve the validity, we used the following means:

1. Professors' opinions,

2. Managers' opinions and management specialists' ideas,

3. Review of articles, books, and similar papers.

To define reliability of the questionnaire, we used the Crombach's Alpha coefficient by SPSS software. Generally, this coefficient was 0.816 , which is larger than the measure of 0.7 . Thus, we can argue that the questionnaire has the required reliability. Finally, data analyzed both descriptively and perceptually. Descriptively, we used redundancy tables to report and, perceptually, the hypotheses examined by using the correlation and multiple linear regression tests. Before that, to determine distribution of samples and to perform appropriate tests, we did the Kolmogorov-Smirnov test.

\subsection{Conceptual Model of Research}

According to the author's studies in the literature, the following conceptual model selected for our research. It is noted that this model manipulated by the author using other models.

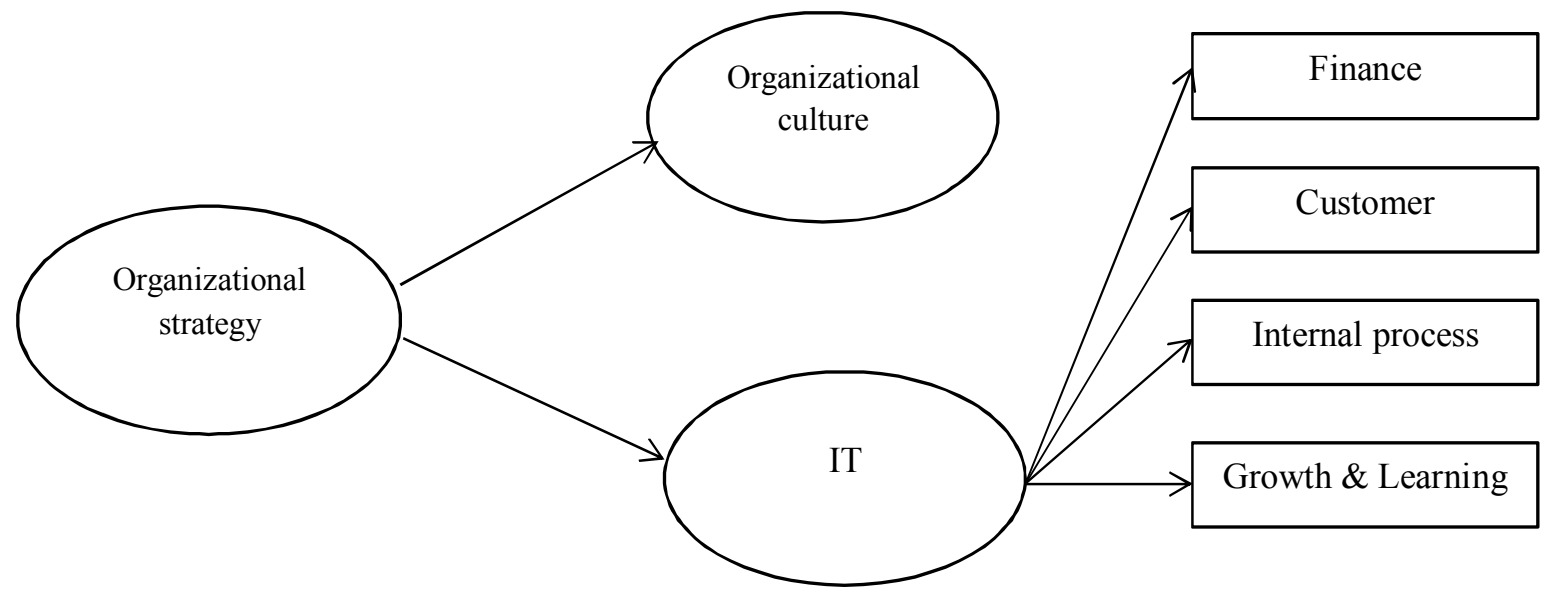

Fig. 1. The proposed study 
Based on the results of Fig. 1, organizational strategy influences positively on information technology (First hypothesis). In addition, organizational strategy influences positively on organizational culture (Second hypothesis). In our survey, $55.6 \%$ of the participants were men and $44.4 \%$ of them were women. Fig. 2 shows other observations associated with the proposed study.

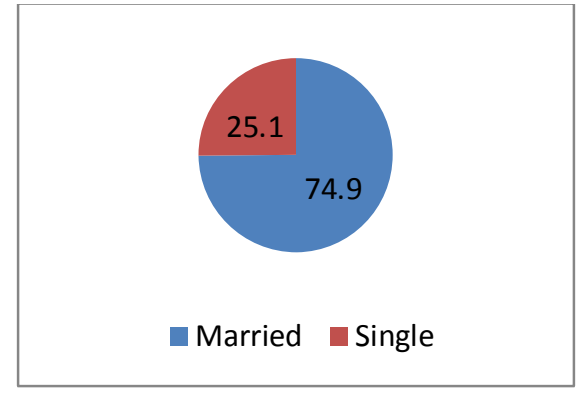

Marital status

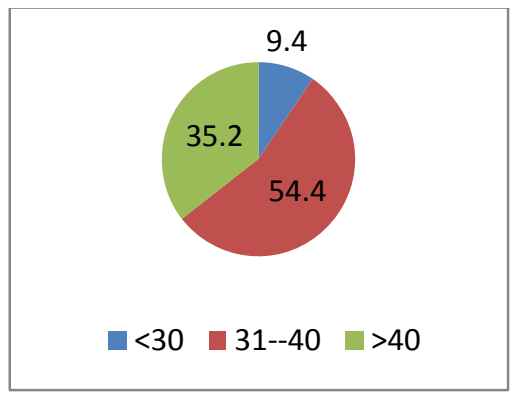

Age

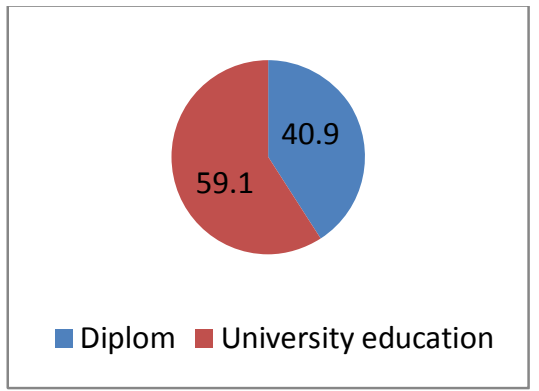

Educational background

Fig. 2. Personal characteristics of the participants

We have applied Kolmogorov-Smirnov test and the results have indicated that the data were normally distributed. Therefore, we use parametric test to verify the hypotheses of the survey.

\section{The results}

In this section, we present details of our findings associated with our investigation. The Pearson correlation between organizational strategy and IT is equal to 0.813 with P-value $=0.001$. In addition, the correlation ratio between organizational strategy and organizational culture is equal to 0.736 with $\mathrm{P}$-value $=0.001$. Hence, we conclude that:

- There is a meaningful relationship between IT and adoption and importance of organization's strategy.

- There is a meaningful relationship between an organization's culture and adoption and significance of its strategy.

Therefore, both hypotheses are proved.

We have also used the multiple linear regression to examine relationship between the variables. After entry the data inputs in the software and performing necessary computations, the following outputs are given in Table 2 as follows,

\section{Table 2}

The summary of regression analysis between organizational strategy (dependent variable) and IT and organizational culture

\begin{tabular}{|c|c|c|c|c|c|}
\hline \multirow[b]{2}{*}{ Model } & \multicolumn{2}{|c|}{ Non-standardized coefficients } & \multicolumn{2}{|l|}{ Standardized coefficients } & \multirow[b]{2}{*}{ Sig. } \\
\hline & B & Standard error & Beta & t-value & \\
\hline Intercept & 28.161 & 3.940 & & 7.148 & 0.712 \\
\hline IT & 2.115 & 1.001 & 0.266 & 2.112 & 0.038 \\
\hline Organizational culture & 1.264 & 0.965 & 0.099 & 1.031 & 0.006 \\
\hline
\end{tabular}

As we can observe from the results of Table 2, IT and organizational variables are statistically significant $(\alpha=5 \%)$. In addition, F-value is statistically significance, which means there is a linear relationship between dependent variable, organizational strategy, independent variables, IT and organizational culture. The result of Adjust R-Square is equal to 0.889, which means the regression analysis represents $89 \%$ of the relationships between independent and dependent variables. 


\section{Conclusion}

This paper has presented an empirical investigation to study the relationship between organizational strategy and organizational culture as well as information technology. Using Pearson correlation test as well as stepwise regression analysis, the study has concluded a positive and meaningful relationship between different components of the survey. In our survey, there seems to be a stronger effect from information technology on organizational strategy compared with organizational culture.

In order to apply strategically the information technology in the organizational level, it needs to plan with scrutiny. Such planning includes deeply study of organizational culture and abilities, introducing changes, external environment of organization, managerial support, and information requirements of organization and how to address them. It is also necessary to examine current organizational skills in the field of IT to ensure that there are adequate and efficient manpower to maintain systems for software and hardware.

Insufficient IT knowledge of managers may create burdens for introducing this technology in organizations. As a result, before bringing IT to serve an organization effectively, it needs to train managers in various fields of technology. However, most managers are heavily busy in massive and technical workload so that there is no room to care of other dimensions of organization's management. The application strategy of IT helps the IT managers avail of existing opportunities during its implementation. To prevent iteration and parallel costs, and to eliminate any delay in big IT development projects, at first, the development strategy should be designed and approved by details of scheduling, achievement tools and methods. Plans of novel technology should shift from manageroriented strategies to plan-oriented. In regulating IT activities, we should define current situation, direction, coordination of efforts, investment framework, budget allocation, managers' commitment and conviction that are to be made in future. The results of this study are consistent with earlier studies including Khalili (2014), Bani et al. (2014) and Chehrazi and Shakib (2014).

\section{References}

Bani, M., Yasoureini, M \& Mesgarpour, A. (2014). A study on relationship between employees' psychological empowerment and organizational commitment. Management Science Letters, 4(6), 1197-1200.

Chehrazi, S \& Shakib, M. (2014). A study on the relationship between emotional intelligence, organizational commitment and organizational citizenship behavior. Management Science Letters, 4(6), 1103-1106.

Henfridsson, O., \& Lind, M. (2014). Information systems strategizing, organizational subcommunities, and the emergence of a sustainability strategy. The Journal of Strategic Information Systems, 23(1), 11-28.

Hyvönen, J. (2007). Strategy, performance measurement techniques and information technology of the firm and their links to organizational performance. Management Accounting Research, 18(3), 343-366.

Khalili, M. (2014). A study on relationship between organizational culture and organizational commitment. Management Science Letters, 4(7), 1463-1466.

Peppard, J., Galliers, R. D., \& Thorogood, A. (2014). Information systems strategy as practice: Micro strategy and strategizing for IS. Journal of Strategic Information Systems, 23(1), 1-10.

Shih, S. P., Lie, T., Klein, G., \& Jiang, J. J. (2014). Information Technology Customer Aggression: The Importance Of An Organizational Climate Of Support. Information \& Management. DOI: 10.1016/j.im.2014.06.001

Yu, Y., Dong, X. Y., Shen, K. N., Khalifa, M., \& Hao, J. X. (2013). Strategies, technologies, and organizational learning for developing organizational innovativeness in emerging economies. Journal of Business Research, 66(12), 2507-2514. 